Biosemiotic Medicine: Healing in the World of Meaning (Studies in Neuroscience, Consciousness and Spiritualityl

Farzad Goli (ed.)

Springer, 2016, HB, 264pp, E64.99, 9783319350912

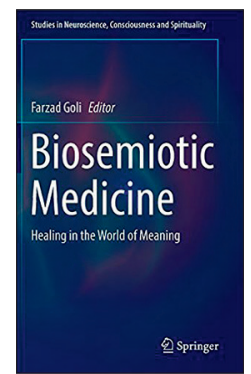

\section{A PARADIGM SHIFT IN BIOLOGY}

Biosemiosis is a new metanarrative that views all of biology in one broad conceptual field of sign (Greek, semion: a sign), relationships extending from animal and human behaviour down to the molecular level. A blood level is information and has meaning when we know the normal range. Context changes information into meaning.

According to Amazon, this book is the first with the words 'biosemiosis' and 'medicine' in the title.

At the molecular level we recognise that the molecule is about something apart from itself. The humble calcium ion is chemically, well, a calcium ion, but when it is involved in blood clotting, muscle contraction, cell mitosis, insulin release, the action potential of the atrioventricular node, it is a sign in a myriad of sign relationships. A sign's meaning is dependent entirely on context.

These ideas of 'aboutness' or sign were partly formalised by the 19th century Harvard mathematician, philosopher, and chemist CS Peirce. He added a second pathway to the simple cause-effect dyad, postulating a double pathway between cause and effect. The sign pathway can have causal effect depending on 'interpretation". These two pathways between cause and effect can be operative at the same time.

In this book Schmidt and Walach present the placebo effect as the sign pathway. They present evidence that $75 \%$ of the analgesic effect of aspirin is due to the placebo effect. They argue that the pharmacological and placebo effects are not independent. We cannot simply 'take away' (in the arithmetic sense) the placebo effect from the total to leave pure pharmacological effect.

Evidence is presented that postoperative pain relief from metamizole is ineffective if the drug is administered at a time unknown to doctor or patient, but effective if seen to be administered by the patient: a very strong example of placebo, or sign causality.

Clearly there is no fixed correspondence between these three entities. These authors conclude that there is little difference between a villager attributing pain relief to an amulet and a pharmacologist attributing $100 \%$ of pain relief in an RCT to the pharmacology.

Carl Scheidt relates the therapeutic effect of a narrative-based consultation to attachment theory and casts the role of physician as a co-constructor of the meaning of the story. He doesn't discount the independent-of-subject observation but suggests both approaches must be kept in balance'; pretty much what we GPs have been trying to do for many a long year.

This approach to biology amounts to a paradigm shift and one that, in its view of neurophysiology, obviates the classic mind-body dualism. It may even provide the sought-after theoretical underpinning of general medical practice and revitalise holism.

Gerald W Partridge,

Retired GP, Keighley, West Yorkshire

E-mail: geraldandbryonyßahotmail.com

DOI: https://doi.org/10.3399/bjgp17X689761

\section{Further reading}

The best introduction to biosemiosis I have found is:

Hoffmeyer J. Biosemiotics: an Examination into the Signs of Life and the Life of Signs. Copenhagen: University of Scranton Press, 2008.

The information/meaning issue is discussed, at some philosophical length, by:

Brier S. Cybersemiotics: Why Information is Not Enough! Toronto: University of Toronto Press, 2008.

Mind-body issues are discussed by the anthropologist Terrence Deacon in:

Deacon TW. Incomplete Nature: How Mind Emerged from Matter. New York: WW Norton \& Company, 2012.

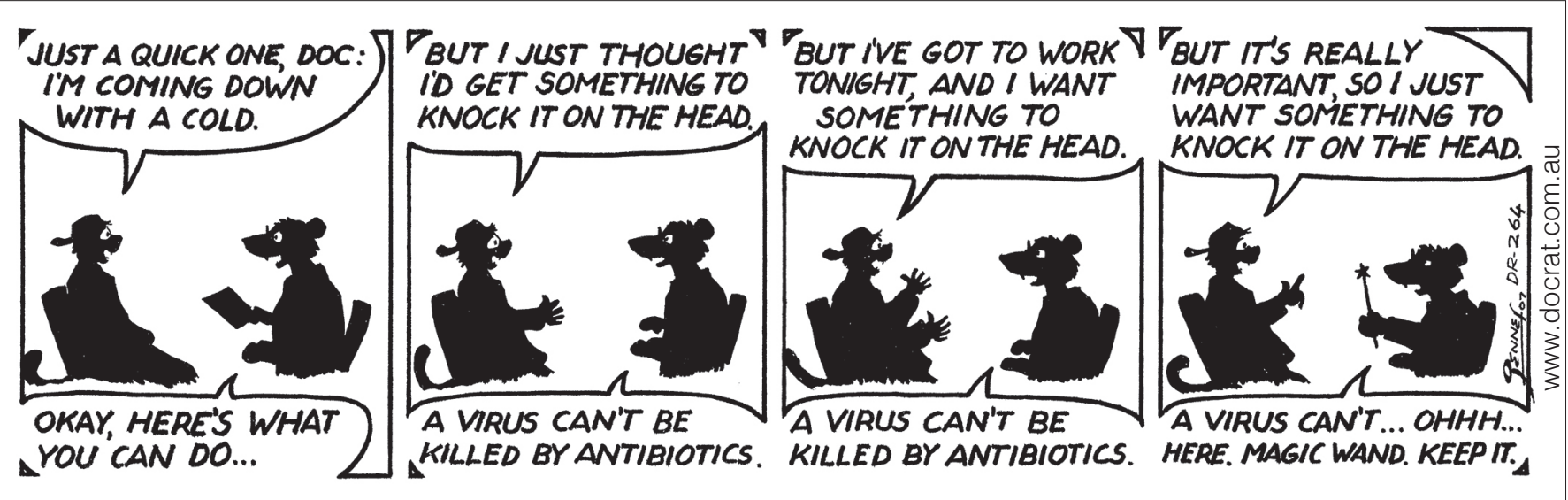

